\title{
A Pragmatic Analysis of Jia Dao's “An Unsuccessful Visit to an Absent Recluse" \\ Congjun Yan
}

School of Foreign Languages, Xian Univesity of Arts and Science, Shaanxi Province,710065,China

Keyword: Literary pragmatics; Reference and inference; Presupposition; Cooperative principle; Perlocutionary act

\begin{abstract}
Literary pragmatics is on the rise. It has bridged the gap between the literature and pragmatics. One of the ways is to look inwardly by applying pragmatic theories of reference and inference, presupposition, cooperative principle and perlocutionary act into literay analysis. Tang poem is the treasure of Chinese literature. Jia Dao's "An Unsuccessful Visit to An Absent Recluse" is a good example of conversation-based structure. So it is a good try to use the pragmatic ways to analyse it in order to pave a way for more poetic studies in a pragmatic perspective.
\end{abstract}

\section{Introduction}

Literary pragmatics is a new interdisciplinary branch of the combination of pragmatics and literature study. It started at 1970s when Van Dijk first used the term, indicating that literature and pragmatics could be put together for cooperative study. Until the year of 1991, Literary Pragmatics was compiled by R. Sell, marking the formal establishment of Literay Pragmatics. (1) Ever since, more and more attentions have been paid to it. It has once again improved the study of both pragmatics and literature greatly not only abroad but also in China.

From 1990s, Chinese scholars stepped into this field. They have deeply explored the nature, characteristics, aim and methods of literary pragmatics(2)(3), and some scholars have already used its theories in doing a lot of specific studies, such as the pragmatic analysis of Emily Bronte's Wuthering Heights(4), John Fowles' Daniel Martin(5), Jane Austin's Pride and Prejudice(6), O. Henry's The Last Leaf(7),Margaret Mitchell's Gone with the Wind(8),etc. These studies have consolidated the literary pragmatics and proved its powerful vitality.

Our great enjoyment, many scholars have also stretched their interests in the study of poetry. They have the idea that poetic language is almost the same as the natural language in communicative functions. From the perspective of pragmatics, the poetry can be easily uncovered that its surface forms, mysterious structures and special language are connected with its meaning generation machinism.(9) At the same time, many scholars have tried their hands in foreign and Chinese poems. Duan Lina, for example, used the foregrounding relationship and speech act theories to analyse Edgar Allan Poe's Annabel Lee and explained its language charm.(10) Gao Lili discussed the problems about English translations of Chinese classical poetry from the perspective of relevance theory.(11) $\mathrm{Wu}$ Liqun also used the relevance theory to specificly analysing the translation of Meng Haoran's peom "Seeing Meng Haoran off at Yellow Crane Tower".(12)These pave the way for later studies. However, these researches have not completed the work. Many of them are still green and leave us a long way to go.

Therefore, this paper will go on the work. A Chinese poem of Tang dynasty will be choisen here for detailed analysis. The inward-looking way is to be used in order to find the charming beauty of the poem.

\section{The Pragmatic Analysis of Jia Dao's “An Unsuccessful Visit to An Absent Recluse”}

Jia Dao was a poet of the Tang dynasty. He was famous for the story of Tuiqiao(scrutiny of dictions for a better meaning). Actually, he was also a sophisticated stylist. This short poem was his masterpiece, well-known for its question-answer structure and profound significance. For convenience' sake, the poem of English translation by Xu Yuanchong is put here for reference.

An Unsuccessful Visit to An Absent Recluse 
Translated by Xu Yuanchong

I asked your lad "neath a pine-tree,

"My master "s gone for herbs," says he.

"Amid the hills I know not where,

For clouds have veiled them here and there."(13)

According to the reference and inference theory, the choice of referring expressions is based on what the speaker assumes the listener already knows and the listener's task is to infer correctly what these referring expressions mean. (14)When we read the first verse line, we may infer that it is the poet to ask the lad though in the Chinese poem the questioner is not given. And at the second line, the questionee is not referred. Logically, we can infer the questionee here is the lad who answered the poet's question. The big problem lies in the last two lines. Are they the answer of questionee's or the utterance of questioner's. The controversy is held for years. Xu's English translation makes it clear that they are the lad's answer(questionee's). Others hold the idea that it is the questioner's utterance after he heard the lad's answer and sighed at very situation. Therefore, poetry, in a sense, is different to the natural conversation in that it may have rich possibilities. These possibilites are sources of the poetic effect, a peculiar effect of a poem that achieves most of its relevance through the weak implicature.

According to the presupposition theory, the unsaid information is assumed by the speaker because it is treated as known. These are speaker's presuppositions. Listeners will get entailments from the utterance. In the poem, the presuppositions may be that there was a recluse in the mountain. The poet went to visit him. Unfortunately, the recluse was out. From the verse lines, these entailments could be known that the recluse must be a real master. He knew the Daothe essence of life and world). His wisdom was veiled by deep clouds and no one really knew how far he had gone in pursuit of knowledge. Otherwise, the poet would not take pains to go visiting him. Actually, in ancient China, wise sages usually chose reclusion. They lived in the mountains to be in harmony with the nature, meditating the truth of the world and enjoyed a natural and worthy life. Or they lived in such a way that they expected sometime their talents could be found by the rulers and then they could be invited to be courtiers serving the dynasties. (15) Therefore, this poem gives such information of Chinese recluse culture via unsaid presuppositions and uttered entailments.

According to H.P.Grice's cooperative principle, both participants of the conversation would be expected to be cooperative, that is, "make your conversational contribution such as is required, at the stage at which it occurs, by the accepted purpose or direction of the talk exchange in which you are engaged." (16)When the poet asked the lad where the recluse was, the lad directly answered him that his master went for herbs. This turn of conversation is well cooperative. But in the third and fourth lines, these questions like "where does your master go for herbs? When does he come back?" are implied but not openly stated. This violates the maxim of quantity because the informative contribution of the speaker is not enough. Meanwhile, these two lines are not the direct answers of those questions. It also violates the maxim of relation and manner. The information that the recluse was in the mountain is so obscure and it is not so specific with unnecessary prolixity. Another information that deep clouds veiled the recluse here and there is also nonsense. Everyone in the mountains will be concealed in the thick forests and big valleys. Obviously, this poem purposely does not abide by the cooperative principle of communication. This is allowed in both natural talks and such poems. The implication of meanings to a poem is derived here that the recluse is not an ordinary man. And at the same time, an overtune of poet's homage and admiration to the recluse is also suggested. That is the very charm of the poem with the question-answer structure effectively.

According to the perlocutionary act theory,(17) conveying information and depicting world are not enough for a conversation. Another function of utterance is to reach some results. Austin defines it as the perlocutionary act. That is actually the effect of a speech act to a hearer on his feelings, thoughts and behavior. In this poem, the poet and lad had a talk about the recluse. After the lad's answer, the poet definitely had diffferent feelings about his visit. He might regret that he could not see the recluse this time. He might envy at the recluse's freedom. He might respect the way of 
reclusion. As the communication between the poet and readers, this poem may pose much greater impact upon the readers. Many Chinese poeple have the potential thought of retirement into a natural life. This poem echoes this and thus is beloved by the posterity. In Chinese culture, this reclusive culture is all the way prosperous and exists up to now.

\section{Conclusion}

Literary pragmatics is a new branch of study. It has a wide use in studying literature. Surely it will have a promising future. These pragmatic theories of reference, speech act, conversational implicature and presupposition, etc will be more and more frequently and effectively applied into future poetry studies. As an instance, this poem contains rich sources of implications. The analysis from the perspective of pragmatics offers a new way to explore it. A good try is attempted here to further development in this field. That is the real value of this paper.

\section{References}

[1] J.Tu: Literary Pragmatics: A New Edge Subject[J], Foreign Languages(Journal of Foreign Languages), 2004,(03):51-56.(In Chinese)

[2] Q.Gao: Research on "Literary Pragmatics" and Its Relevance of China since the $21^{\text {st }}$ century[J], Journal of Fujian Normal University (Philosophy and Social Sciences Edition), 2016,(02):99-106+225-226.(In Chinese)

[3] J.Tu: Towards Theoretical System of Literary Pragmatics[J], Foreign Language Research, 2011,(02):88-91.(In Chinese)

[4] L.Hua: Pragmatic Analysis of Conversations Excerpted from Wuthering Heights[J], Journal of Suzhou College of Education, 2011,28(01):44-47.(In Chinese)

[5] W.X.Wang and J.Y.Zhu: Speaker Present and Story Present: A Literary Pragmatic of John Fowles' Daniel Martin[J], Journal of Zhejiang International Studies University, 2013,(02):45-50.

[6] Y.Xie: Interpretation of Character Dialogue in Pride and Prejudice Based on the Perspective of Politeness Principle[J], Masterpieces Review, 2016,(27):114-115+118.(In Chinese)

[7] S.H.Zhang and L.Ma: On Characters' Language from Politeness Principle in O.Henry's The Last Leaf [J], Journal of Hefei University of Technology(Social Sciences), 2015,29(04):122-126.(In Chinese)

[8] F.L.Zhong: Verbal Irony from the Speech Act Theory: Take Gone with the Wind as an Example[J], Journal of Hebei University of Technology(Social Sciences), 2014,6(03):82-87.(In Chinese)

[9] F.G.Liu and W.X.Yang: Exploring Poetic Discourse from a Pragmatic Perspective[J], Journal of Northwest Normal University(Philosophy and Social Sciences), 2006,(05):114-118.(In Chinese)

[10] L.N.Duan: An Analysis of the Literary and Pragmatic Perspectives of Annabel Lee[J], Language Planning, 2015,(26):75-76.(In Chinese)

[11] L.Y.Gao: English Translation of Chinese Classical Poetry from the Perspective of Relevance Theory[J]. Journal of Zhejiang Business Technology Institute, 2017,16(03):28-30.(In Chinese)

[12] L.Q.Wu: Analysis of the Translations of "Huanghe Lou Song Meng Haoran Zhi Guangling" from the Perspective of Relevance Theory[J], Journal of Mudanjiang Normal University(Philosophy and Social Science Edition), 2012,(01):102-104.(In Chinese)

[13] Y.C.Xu: A New Translation of the Three Hundred Poems of the Tang Dynasty (Both English and Chinese) [Z] Beijing: China Translation Corporation, 1988, 308.(In Chinese)

[14] George Yule. Pragmatics=Pragmatics, Shanghai: Shanghai Foreign Language Education Press, 2000, 16.(In Chinese)

[15] W.Z.Chen: Modernity of the Top Poem of Inquiring for recluse in the Tang Dynasty[J], Journal of Anhui Normal University(Human and Social Sciences), 2005,(02):140-147.(In Chinese)

[16] Z.X.He: Selected Readings for Pragmatics=Selected Readings for Pragmatics, Shanghai: Shanghai Foreign Language Education Press, 2003, 370.(In Chinese) 
[17] Austin,J.A., How to do things with words[M].Oxford:Oxford University Press.1980[1962],101.(In Chinese) 